\title{
Performance Analysis of Various Characteristics on Dry Drilling Hole Quality Of 17-4 PH Stainless Steel with Solid Carbide Drill Bits
}

\author{
Kamlesh Mandpe ${ }^{1}$, Sharda Pratap Shrivas ${ }^{2}$, Aruna Thakur ${ }^{3}$ \\ ${ }^{1}$ M. Tech Scholar, Chouksey Engineering College Bilaspur, Chhattisgarh 495004 \\ ${ }^{2}$ Assistant Professor, Chouksey Engineering College Bilaspur, Chhattisgarh 495004 \\ ${ }^{3}$ Assistant Professor, National Institute of Foundry and Forge Technology, Ranchi, Jharkhand 834003 \\ Corresponding author, E-mail address: pratapshrivas34@gmail.com \\ Received Oct'16, 2019; received in revised form Jan'23, 2020; Accepted Jan' 23, 2020
}

\begin{abstract}
17-4 PH stainless steel is one of the most imperative grades of precipitation hardened aerospace grade stainless steel particularly used in aircraft, marine vessels, nuclear industries, turbine blades, food processing equipment and oil \& gas industry. It belongs to the class of difficult to cut material because of its unique properties such as high strength, high hardness and toughness including good corrosion resistance. The present study deals with comparative analysis of hole quality, surface roughness and chip characteristics when drilling 17-4 PH stainless steel with both uncoated and coated solid carbide drill bits. Dry drilling operation was carried out at two different feed of $0.10 \mathrm{~mm} / \mathrm{rev}$ and $0.15 \mathrm{~mm} / \mathrm{rev}$ with a constant spindle speed of 2000 RPM. Results indicated that surface finish and burr thickness could not be improved, while remarkable reduction in hole diameter and delamination factor was noted for the coated solid carbide drill bit compared to its uncoated counterparts for different machining conditions.
\end{abstract}

Keywords - 17-4 PH stainless steel, Hole quality, Burr thickness, Delamination factor, Surface roughness, Chip morphology, Carbide drill bits.

\section{Introduction}

In recent years precipitation hardened steels have been assumed as considerable research interest owing to their wide engineering application particularly in strategic environment. 17-4PH stainless steel or $0 \mathrm{Cr} 17 \mathrm{Ni} 4 \mathrm{Cu} 4 \mathrm{Nb}$ is a martensitic precipitation hardened stainless steel [19], with a microstructure that is mainly austenitic at elevated temperature but transform into martensitic structure when brought down to room temperature along with high rate of cooling. It contains nearly $3-4 \%$ of $\mathrm{Cu}$ by weight. Its microstructure at different stages of heat treatment i.e. after solution heat treatment, tempering at 5400C and long-term precipitation hardening at $4000 \mathrm{C}$ have been calculated by atom probe field ion microscopy (APFIM) and transmission electron microscopy (TEM) [12]. It is also found that after a solution treatment, steel produces a uniform matrix, which consists of lathe martensite with micro-twins [6]. 17-4 PH stainless steel plays an extremely important role in the field of industry in manufacturing of medical material and different other high corrosion applications. The machining of stainless-steel materials gives less tool life, high cutting force, limited material removal rate and high-power consumption, because of high value of temperature, reactivity with other materials at high machining speed and rapid work hardening during machining [8]. Four distinct burr types are evaluated during drilling of titanium alloy plates [5]. Furthermore, optimal cutting parameter regarding performance indexes like tool life \& burr height has been investigated [8]. The influencing factors of cryogenic treatment on 
performance of M35 HSS drill bits during drilling of AISI 316 austenitic stainless steel in terms of tool life, surface roughness, hole diameter, cutting force and error in roundness has been investigated [4]. Producing holes is one of the common but complex operation as well compare to different machining processes because it poses problems including complete prevention of burr formation is almost impossible. These issues have been solved by availing variable feed machining that improves tool life as well [7].

Precipitation hardened steels belong to an interesting family of steels due to its heat treatment characteristics and combination of good corrosion resistance, high strength, excellent weldability and high hardness up to 49HRC [1]. These properties make them attractive choice for application in aerospace industries. 17-4 PH stainless steel has potential to replace titanium alloy in certain applications to minimize material cost. It is used to manufacture heavy load components such as fasteners, valves, aircraft fittings, gears, couplings, hydraulic actuators, chemical processing equipment, oil \& gas refineries, rocket \& missile components, design steam turbine, jet engines, parts of nuclear reactors, pump shafts, wear rings [9,20,21].

The surface of cutting tool need to have enough surface hardness, toughness, low coefficient of friction, high wear resistance and chemical inertness and core should have good strength, toughness, hot hardness and high thermal conductivity. Cutting tool must have their properties both at surface and core, to make it possible coating deposited on surface of the tool to gain desire properties [11]. It is evident that CVD multilayer coated tool produce more machined surface roughness compare to its uncoated components [16]. The effect of coating materials, coating layers and drilling conditions on cutting forces has been studied [2]. It is evaluated that machining at variable feed and speed is a significant method to enhance the performance of cutting for hard to cut materials and the 17-4 PH stainless steel is also belong to the same category $[3,10,17]$. It is evident that variable feed machining is better to constant feed machining with respect to tool life, surface roughness and burr height [7]. The burr formation during drilling 304 stainless steel is majorly influenced by tool wear which also affects hole quality, surface roughness and tool life [13]. It's very crucial to have knowledge about chip formation mechanism during dry drilling of any kind of material to deliver the chip with shape and size. Since long chips cant not flow out smoothly over drill flutes, hence it must be avoided while broken and small type chips can be removed easily from the machined hole chip formation when drilling AISI 316L. Lowest cutting speed and lowest feed rate lead to better performance due to desirable chip formation during drilling austenitic stainless steel [15].

Since research on comparative study regarding hole characteristics and chip morphology during drilling 17-4 PH stainless steel with using uncoated and coated solid carbide drill bits is scarce. Therefore, the aim of the present work is to evaluate the performance of uncoated and coated drill bits to find out hole quality (diameter), delamination factor, burr thickness, surface roughness and chip morphology with variable feed rate of $0.10 \mathrm{~mm} / \mathrm{rev}$ and $0.15 \mathrm{~mm} / \mathrm{rev}$ and at constant spindle speed of 2000 RPM.

\section{Experimental details}

A heavy-duty CNC machine (FANUC series Oi Mate-MC MAXMILL) was used for the purpose of conducting experiment. A rectangular plate of 17-4 PH stainless steel with $150 \mathrm{~mm}$ length, 90 $\mathrm{mm}$ width and $12 \mathrm{~mm}$ thickness were used as 
workpiece. Figure 1 shows photographic view of experimental setup for dry drilling of 17-4 $\mathrm{PH}$ stainless steel.

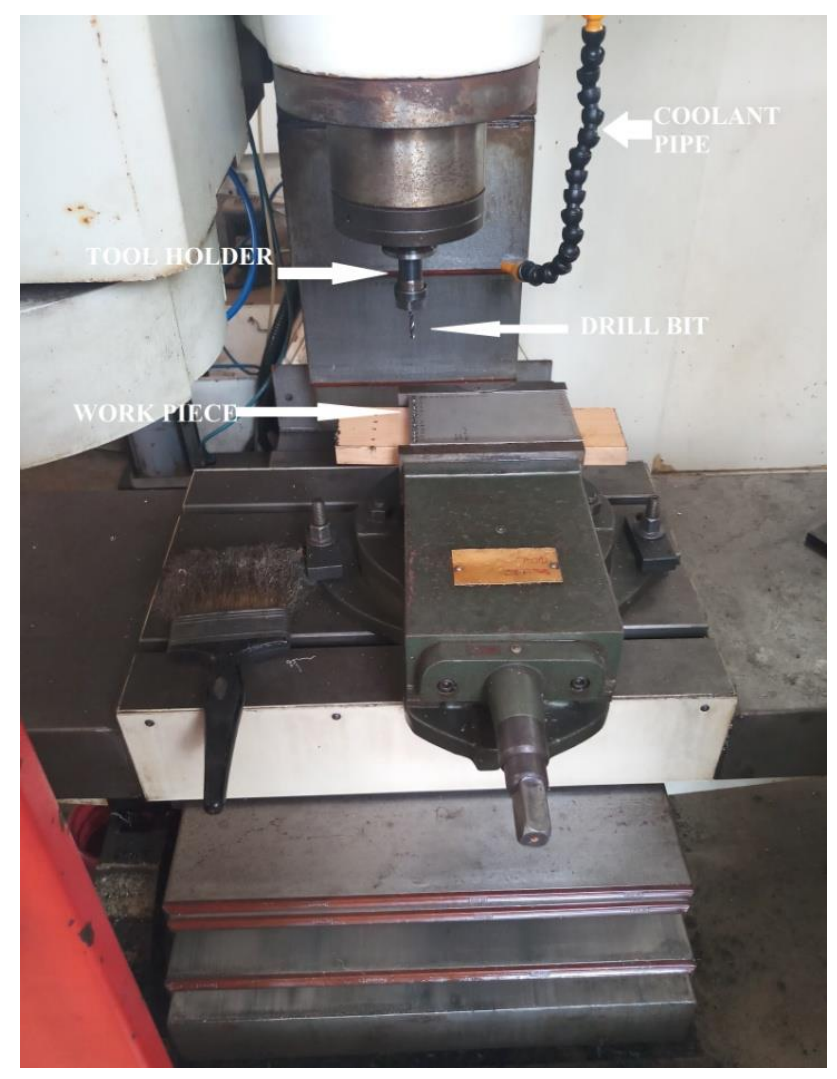

Figure 1 Experimental setup for dry drilling of 17- 4PH stainless steel

Chemical composition of 17-4 PH stainless steel is represented in Table $1 \&$ Table 2 shows the properties of 17-4 PH stainless steel. The drilling operation was carried out with constant spindle speed of 2000 RPM at two distinct feed rates of $0.10 \mathrm{~mm} / \mathrm{rev}$ and $0.15 \mathrm{~mm} / \mathrm{rev}$. The performance of uncoated solid carbide drill was compared with that of coated solid carbide drill bit (ICCR11GDR005x5) $4 \mathrm{~mm}$ flute diameter, $22 \mathrm{~mm}$ flute length, $54 \mathrm{~mm}$ overall length and $4 \mathrm{~mm}$ shank diameter. Make, series C1GS (stub series) Make:
ROHIT cutting tools, INDIA) was used in overall experiments.

Table 1 Chemical composition of 17-4 PH stainless steel

\begin{tabular}{|l|l|l|l|l|l|l|l|l|}
\hline Element & $\mathrm{Ni}$ & $\mathrm{Si}$ & $\mathrm{Zn}$ & $\mathrm{Cr}$ & $\mathrm{Fe}$ & $\mathrm{S}$ & $\mathrm{Cu}$ & $\mathrm{Mn}$ \\
\hline $\begin{array}{l}\text { Weight } \\
\%\end{array}$ & 3.1 & 2 & 1.8 & 15.8 & 63.9 & 0.4 & 12.2 & 0.8 \\
\hline
\end{tabular}

Table 2 Properties of 17-4 PH stainless steel

\begin{tabular}{|l|l|}
\hline Density, $\mathrm{g} / \mathrm{cm}^{3}$ & 7.78 \\
\hline Specific Heat $(\mathrm{J} / \mathrm{kg})$ & 460 \\
\hline Thermal expansion co-efficient $\left(\mu \mathrm{m} / \mathrm{m}^{\circ} \mathrm{C}\right)$ & 10.3 \\
\hline Modulus of Rigidity $(\mathrm{GPa})$ & 67 \\
\hline Poisson's ratio & 0.272 \\
\hline Elastic modulus $(\mathrm{GPa})$ & 197 \\
\hline Mean coefficient of thermal expansion $(\mu \mathrm{m} / \mathrm{mK})$ & 10.4 \\
\hline
\end{tabular}

The chip morphology and conditions of the tool after machining were analyzed by scanning electron microscopy (SEM, Make: JEOL JSM6400). Surface roughness measured using a roughness tester (Make: Taylor Hobson, model: surtronic3+) at four different locations for each run and then average value is taken into consideration.

Such plan of experiment would also enable understanding of influence of cutting duration on various aspects of machining of 17-4 PH stainless steel while compare to the performance of uncoated and coated solid carbide drill bits. To get the better statistical accuracy of measured responses each experiment run was repeated thrice. 

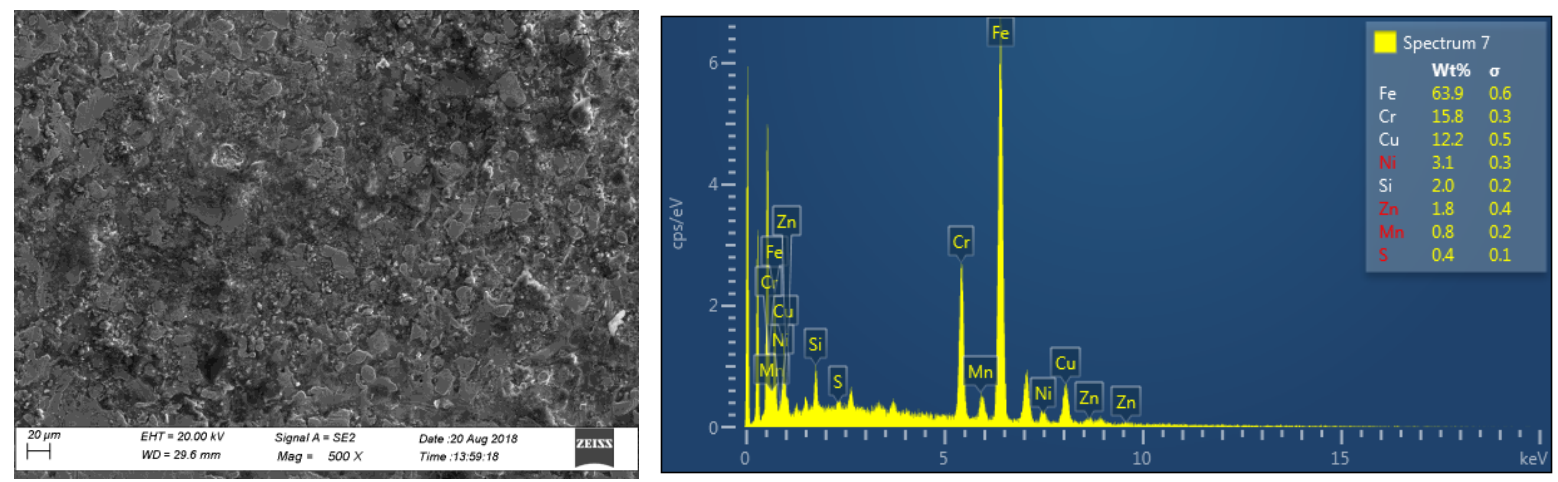

Figure 2 SEM image of microstructure and EDS spectrum of received 17-4 PH stainless steel

\section{Result and discussion}

3.1 Characterization of tools

The SEM image of carbide drill bit which was used in machining of 17-4 PH stainless steel along

(a)

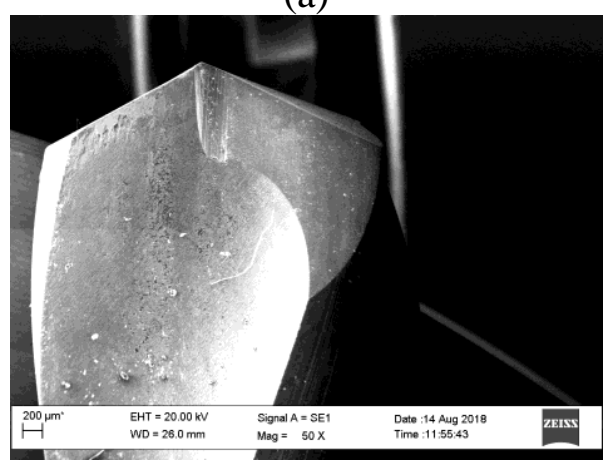

with the EDS spectra of uncoated solid carbide drill after machining are represented in Figure 3.

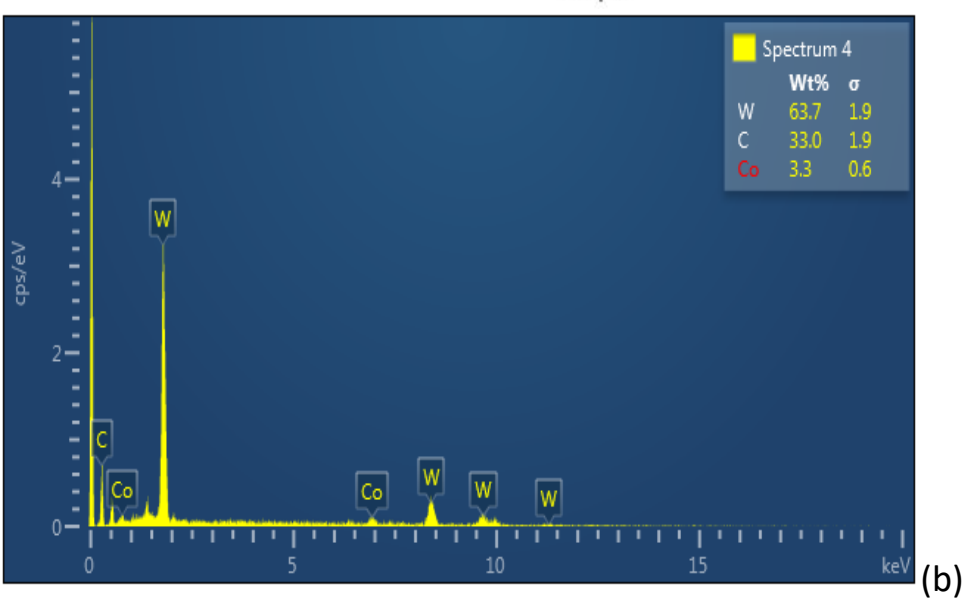

Figure 3 (a) SEM Image of carbide drill bit before machining

(b) EDS Image shows its composition

\subsection{Surface roughness}

Measurement of surface roughness after drilling the quality of the machined surface. Figure 4 which is an important criterion for determining represented SEM images of machined surfaces of 
holes drilled by uncoated and TiAlN coated solid carbide drill bits. Figure 5 shows the variation of surface roughness of 17-4 PH stainless steel with variable feed rate for successive holes at same spindle speed with using uncoated and TiAlN coated drill bits. There is a gradual increase in surface roughness with increasing feed rate and progressive number of holes. It represents the surface finish of the machined surface is deteriorated gradually with increasing feed rates at the same speed. Several severe frictional rubbing actions with formation of built up edge (BUE) and built up layer (BUL) within the specified cutting range was responsible for worsening surface finish [20]. It is also evident that for the different feed rates the surface finish of drilled surface could not be improved by the TiAlN coated solid carbide drill bit compared to its uncoated carbide drill bit for dry drilling of 174 PH stainless steel.

\subsection{Hole Quality}

Characteristics of drilled hole were studied using scanning electron microscopy (SEM). The images of the successive holes with high magnification SEM images were captured and analyzed that is shown in Figure 5. Also, variation of hole diameter with different feed rates for successive holes with using uncoated and TiAlN coated solid carbide drill bit is shown in Figure 6. It is evident that the hole quality degraded chronologically for successive holes and when increasing feed rate hole quality becomes slightly improved.

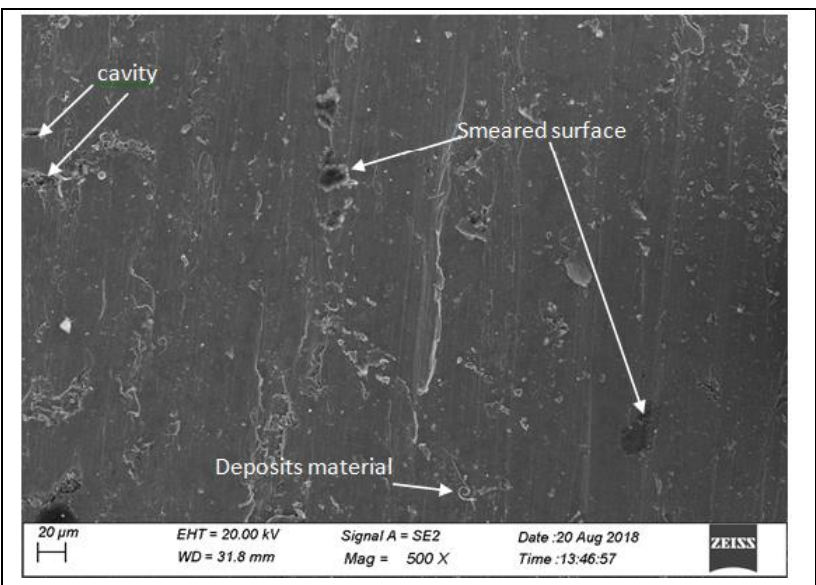

a)
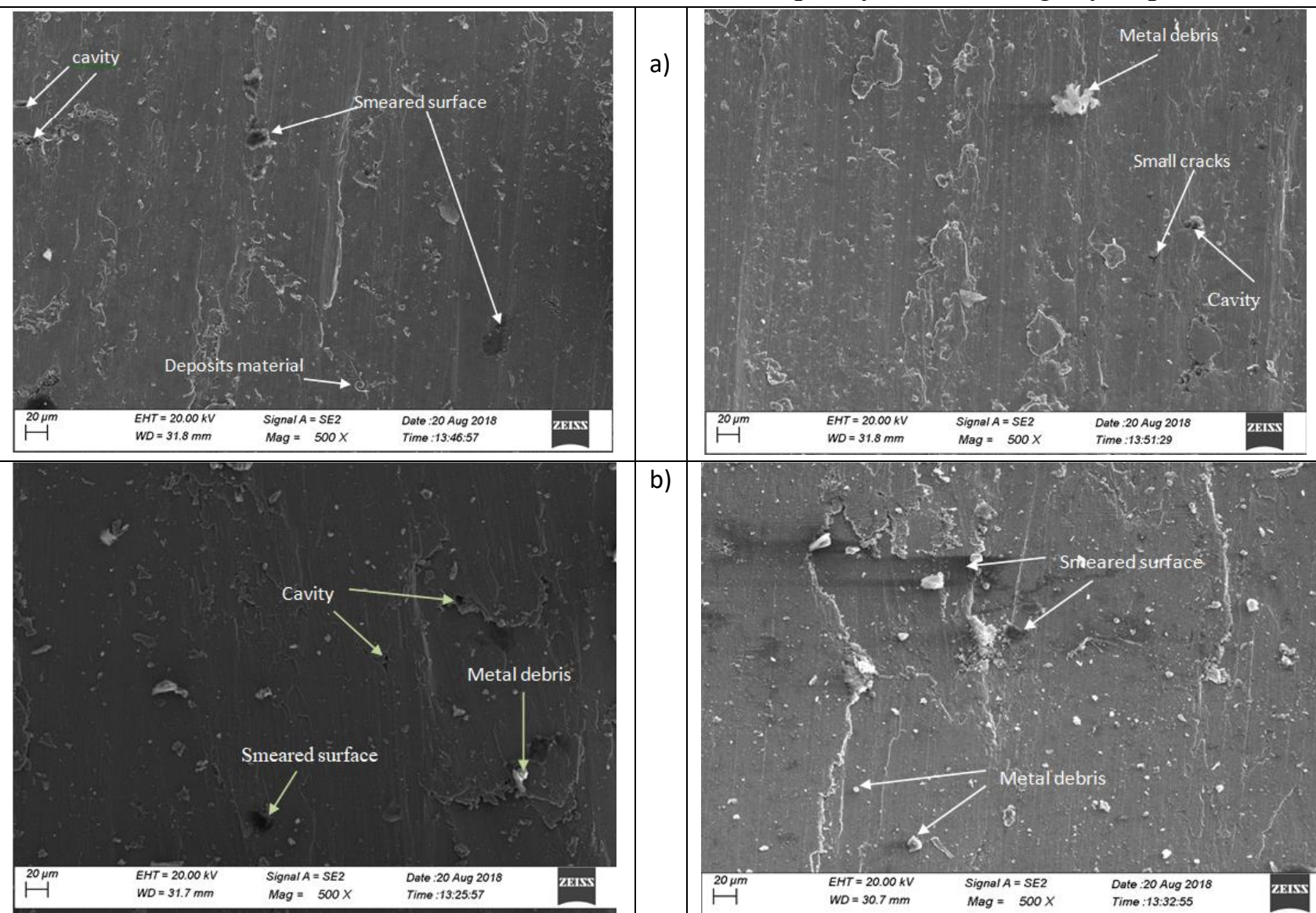

b)

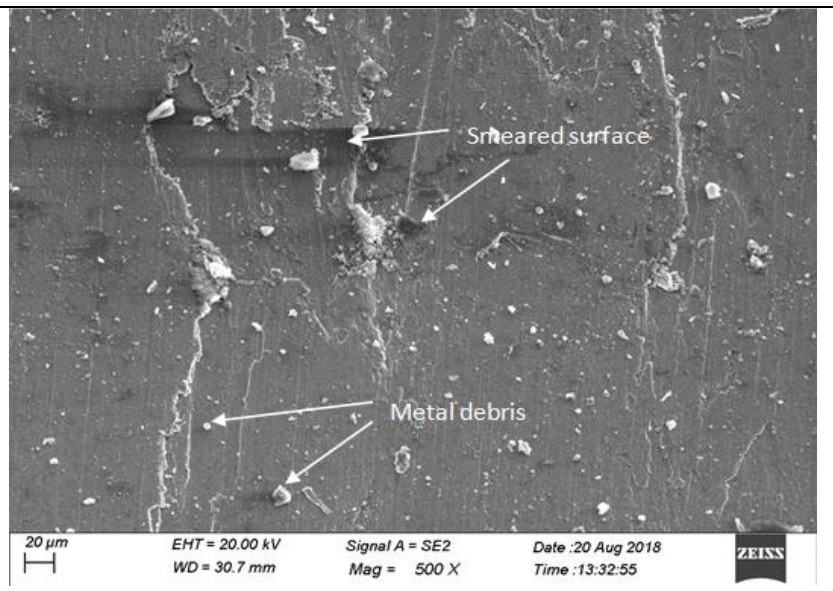

Figure 4 SEM Image of drilled surface of 17-4 PH stainless steel at variable feed rates and constant spindle speed of 2000

RPM (a) At feed $=0.10 \mathrm{~mm} / \mathrm{rev}$; (b) At feed $=0.15 \mathrm{~mm} / \mathrm{rev}$ 
It is also found that for a same feed rate the hole quality could be improved by using TiAlN coated solid carbide drill bit as compared to uncoated carbide drill for dry drilling of 17-4 PH stainless steel.

\section{UNCOATED}
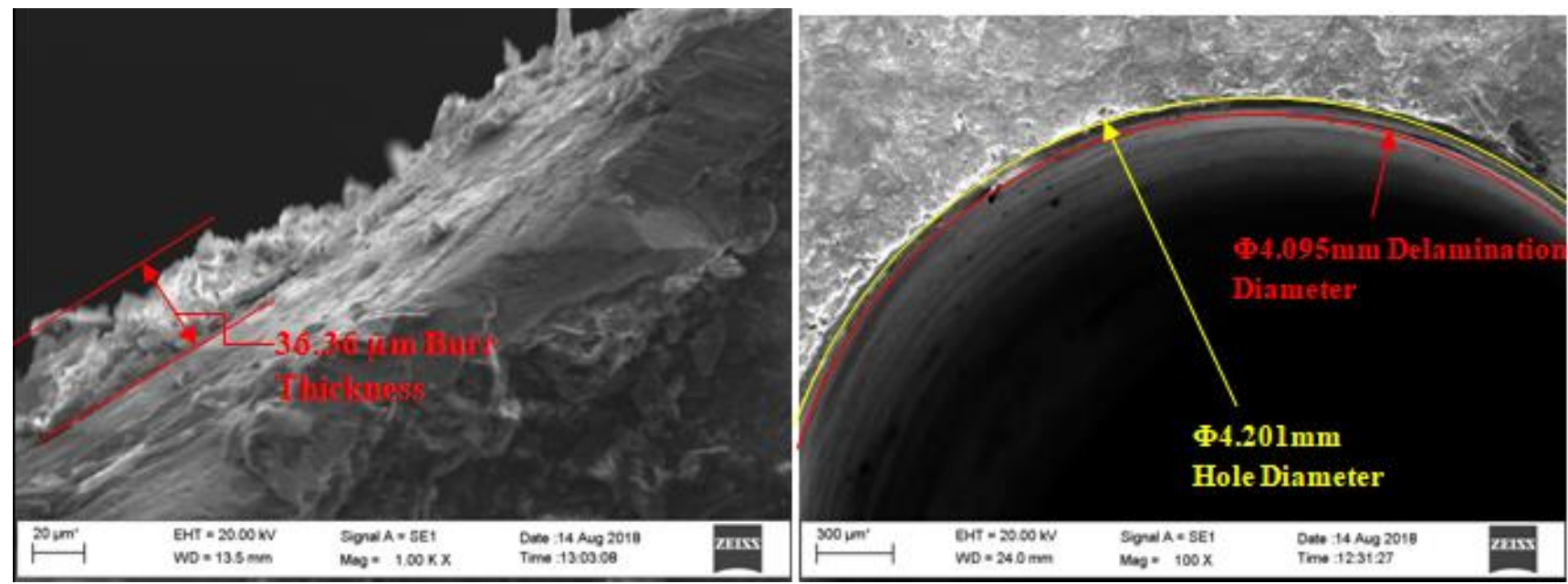

\section{COATED}

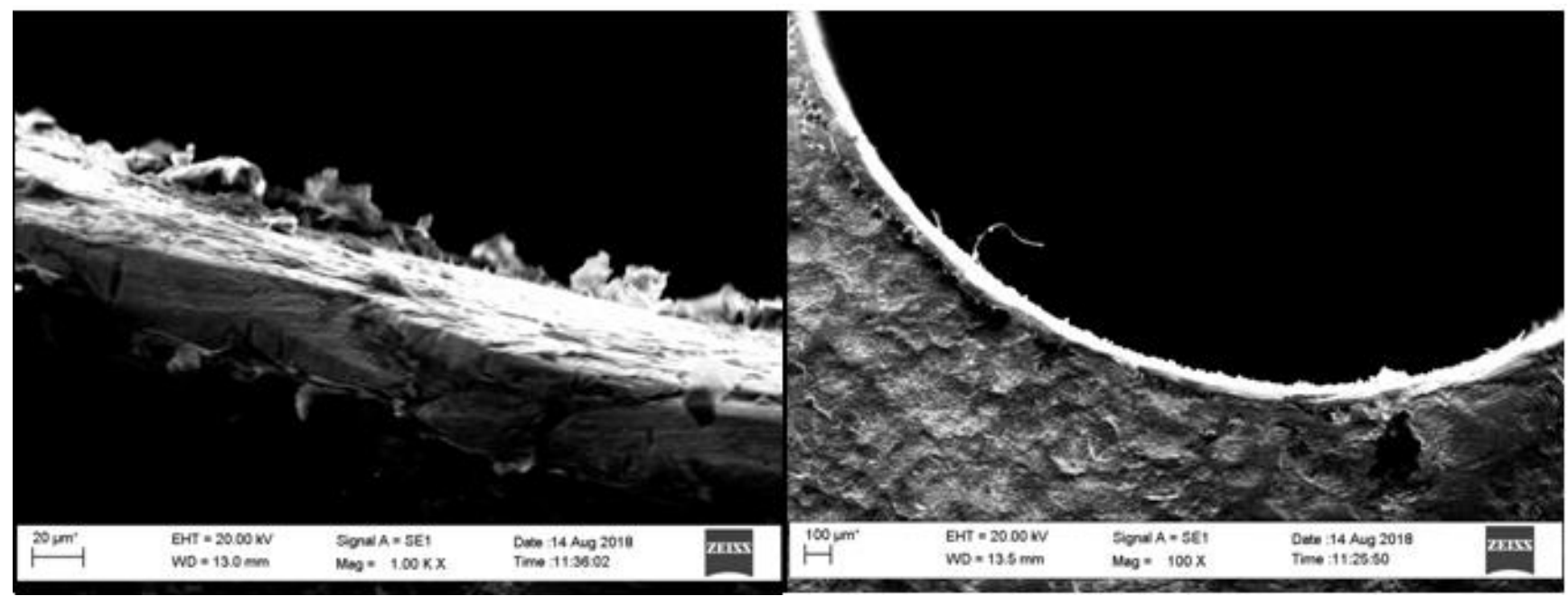

Figure 5 (a) Characteristics of hole quality with same spindle speed but different feed rates $(0.10 \mathrm{~mm} / \mathrm{rev})$ 


\section{UNCOATED}

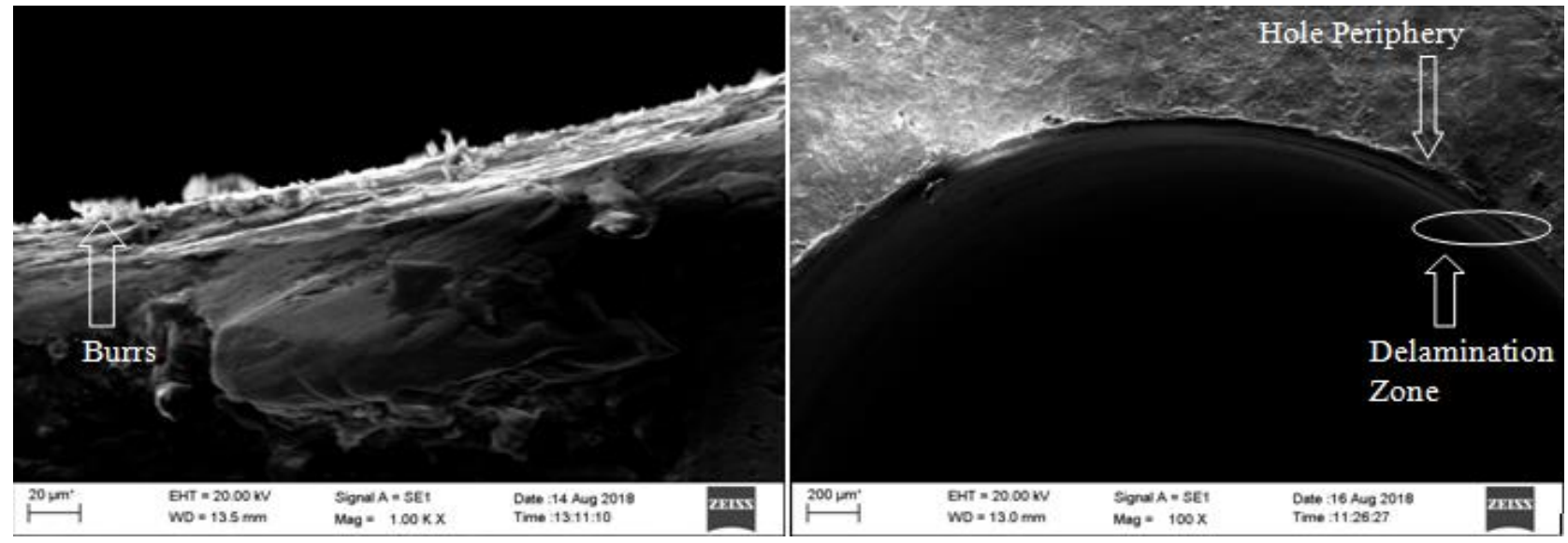

\section{COATED}

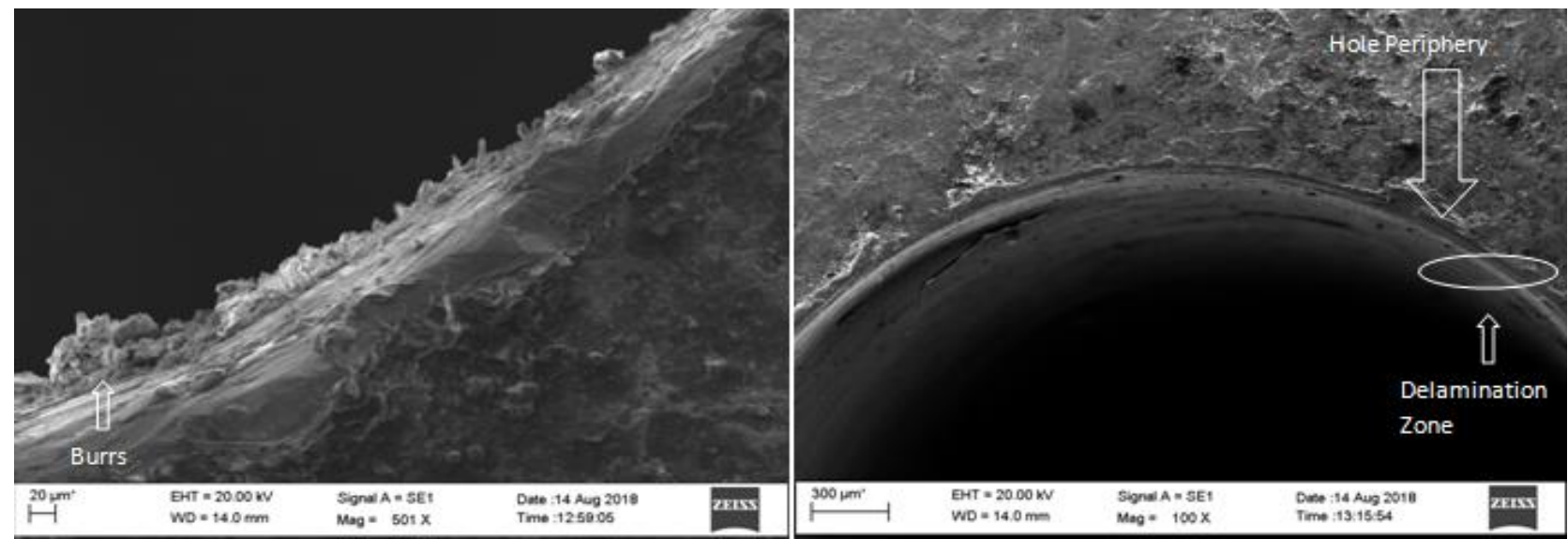

Figure 5 (b) Various characteristics of hole quality with same spindle speed but different feed rates (At $0.15 \mathrm{~mm} / \mathrm{rev}$ )

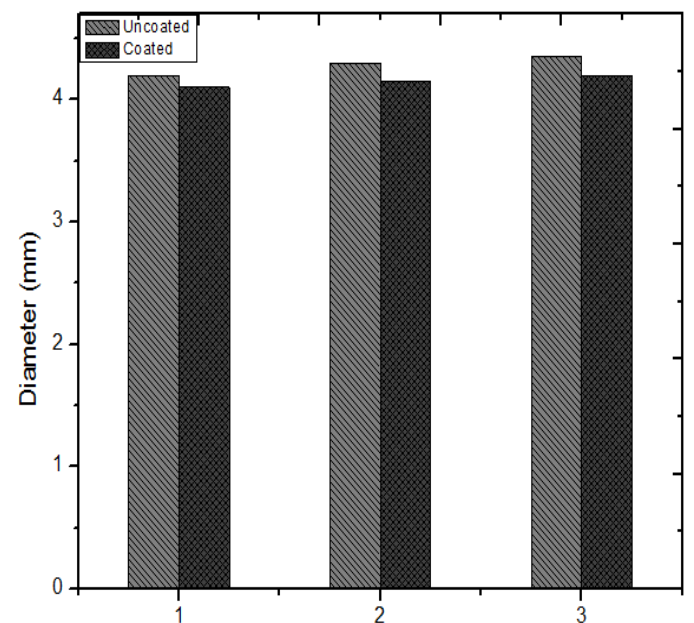

(a)

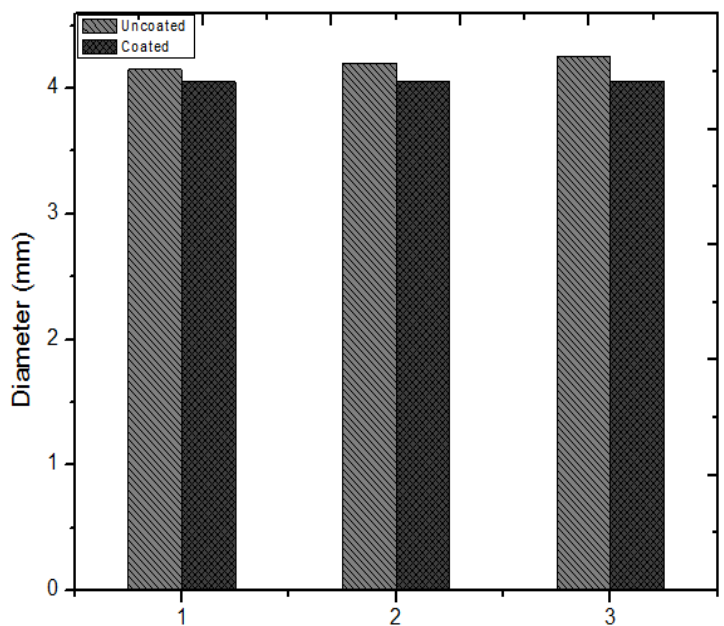

(b)

No. of holes

Figure 6 Variation in hole Diameter with two feed rates and constant speed of 2000 RPM for successive number of holes.

(a) At feed $=0.10 \mathrm{~mm} / \mathrm{rev}$, (b) At feed $=0.15 \mathrm{~mm} / \mathrm{rev}$. 


\subsection{Delamination factor}

In order to measure delamination factor, a circle that covering all the delamination damages was plotted which was concentric to the circle which is approximately to the periphery of the hole. The outer hole diameter was measured as (Dlam). The delamination factor $(\mathrm{Fd})$ was calculated by the equation (1) [14].

$$
\mathrm{Fd}=\mathrm{Dlam} / \mathrm{D}
$$

Where, Dlam is the diameter of the delaminated
The delamination zone is represented in Figure 5, and the variation of delamination factor with variable feed rate for successive holes at the same spindle speed using uncoated and coated carbide drill is shown in Figure 8. It is evident that the delamination factor is slightly increased with raise on feed rate. Also the delamination factor could be decreased by using TiAlN coated solid carbide drill for a particular feed rate and spindle speed for dry drilling of 17-4 PH stainless steel. zone and $\mathrm{D}$ is the nominal tool diameter.

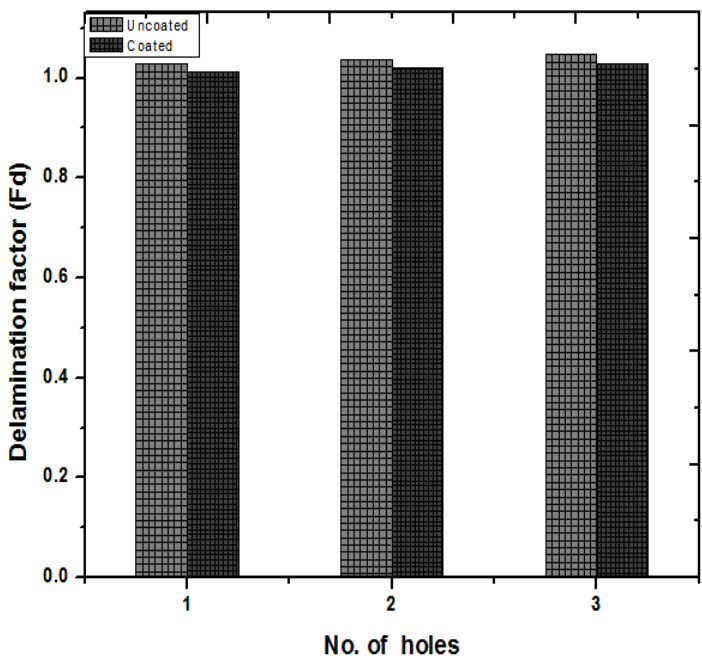

(a)

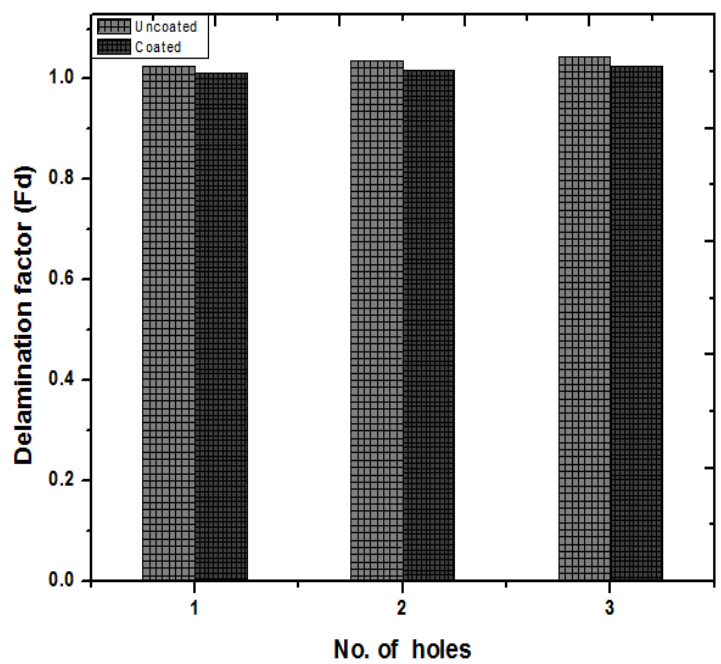

(b)

Figure 8 Variation in Delamination factor $(\mathrm{Fd})$ with two different feed rates and at a constant speed for successive number of holes. (a) At feed $=0.10 \mathrm{~mm} / \mathrm{rev}$, (b) At feed $=0.15 \mathrm{~mm} / \mathrm{rev}$.

\subsection{Mean burr thickness}

Influence of feed rate on different hole characteristics including burr thickness is represented by SEM image which is shown in Figure 5. The variation in burr thickness with variable feed rate for successive holes at the constant speed while drilling 17-4 PH stainless steel drilled by uncoated solid carbide drill bit and TiAlN coated solid carbide drill bits, is shown in Figure 9. It is found that with increase in feed rate the mean burr thickness is gradually increased for a constant spindle speed. It is also found that using TiAlN coated solid carbide drill bit could not be decreased the value of burr formation. Along with this the mean burr thickness is found to be increased when drilled with a coated carbide drill bit at a particular value of feed rate and spindle speed.

\subsection{Chip morphology}

Macro morphology of chip after dry drilling of 17-4 PH stainless steel using uncoated and TiAlN coated solid carbide drill bits with variable feed rates and constant spindle speed for all successive holes that has been shown in Table 3. The type or 
form of chips in current study has been classified according to ISO 3685-1977(E).

a)
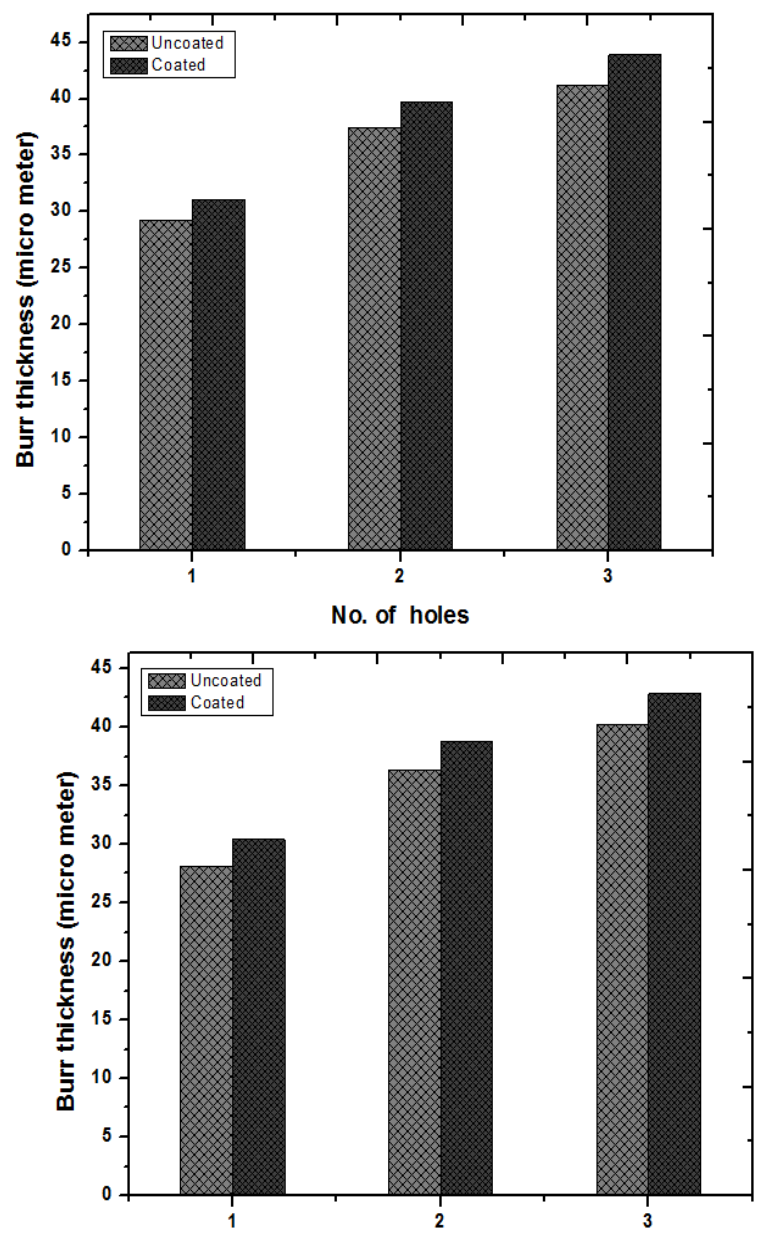

(b)

No. of holes

Figure 9 Variation in mean burr thickness with two feed rates and at a constant speed for successive holes. (a) At feed= $0.10 \mathrm{~mm} / \mathrm{rev}$, (b) At feed $=0.15 \mathrm{~mm} / \mathrm{rev}$.

The chip produced from dry drilling operation under previously mentioned machining condition for both types of drill bits are broken type, spiral (tight helix \& loose helix), long ribbon type, continuous broken tubular type and continuous type. The long continuous type chips are majorly obtained during machining of ductile materials. Higher toughness of ductile materials tends to absorb the energy required for shearing and tearing resulting in formation of continuous type of chips. Growth of tool wear leads to modification of cutting-edge geometry which is turning in responsible to form curl and thus tubular type of chip.

It is evident from Table 3 that the type of chip at 2000 spindle speed and $0.10 \mathrm{~mm} / \mathrm{rev}$ feed rate were well broken and spiral (tight and loose helix) type chips has been formed. While using higher feed rate of $0.15 \mathrm{~mm} / \mathrm{rev}$ at the same speed initially spiral chips then long ribbon type subsequently continuous but broken type tubular chips are formed when drilled with uncoated drill bits and besides this broken, serrated (ribbon like) type chips and subsequently continuous type of chips are formed when drilling with TiAlN coated solid carbide drill bits. Free surface of chips produced during dry drilling of 17-4 PH stainless steel was examined using SEM.

Figure 10 shows the SEM images of the free surface of the chips which were obtained during drilling with uncoated and TiAlN coated solid carbide drill bits at constant speed but variable feed rates. The images depicted that the formation for primary serrated teeth, secondary serrated teeth, chips material flow from side tip of chip and micro hole and cracks formation.

Table 3 Morphology of chips for both uncoated and coated drill bits at same spindle speed and variable feed rates.

\begin{tabular}{|l|c|c|c|c|}
\hline $\begin{array}{l}\text { No. of } \\
\text { Holes }\end{array}$ & \multicolumn{2}{|c|}{ Feed rate $=0.10 \mathrm{~mm} / \mathrm{rev}$} & \multicolumn{2}{c|}{ Feed rate $=0.15 \mathrm{~mm} / \mathrm{rev}$} \\
\hline & Uncoated & Coated & Uncoated & Coated \\
\hline
\end{tabular}




\begin{tabular}{|c|c|c|c|c|}
\hline $\begin{array}{c}\text { Hole } \\
1\end{array}$ & $\begin{array}{l}\text { Broken type chips, } \\
\text { silver color }\end{array}$ & Broken type chips, & Spiral (loose helix) & Broken Chips, \\
\hline $\begin{array}{c}\text { Hole } \\
2\end{array}$ & Spiral (tight helix) & Spiral (tight helix) & Long ribbon type & $\begin{array}{l}\text { Serrated ( ribbon } \\
\text { like) chips, silver } \\
\text { color }\end{array}$ \\
\hline $\begin{array}{c}\text { Hole } \\
3\end{array}$ & Spiral (loose helix) & $\begin{array}{l}\text { Loose helix (short } \\
\text { ribbon like) broken } \\
\text { type chips, silver } \\
\text { color }\end{array}$ & $\begin{array}{l}\text { Continuous but } \\
\text { broken tubular type } \\
\text { chips, silver color }\end{array}$ & $\begin{array}{l}\text { continuous type } \\
\text { chips, silver color }\end{array}$ \\
\hline
\end{tabular}

\section{Conclusion}

The current research work investigated the effect of tool coating and variable feed rates in different machining characteristics of hole produced during dry drilling of 17-4 $\mathrm{PH}$ stainless steel by simulation and experimentation. From this study the following conclusion may be drawn:

1. Elevation in feed rate lead to increment in surface roughness. Also, it could not be improved by using TiAlN coated drill at specific machining conditions which were taken.

2. The delamination factor as well as burr thickness increased when feed rate was raised from 0.10 to $0.15 \mathrm{~mm} / \mathrm{rev}$. Moreover, the burr thickness increased for successive three holes which were drilled at a particular feed rate and drill bit type. Variation in these machining characteristics is also represented with the help of simulated results. 
3. Hole diameter improved when feed rate was increased from 0.10 to $0.15 \mathrm{~mm} / \mathrm{rev}$. Also, the hole diameter improved by drilling with using TiAlN coated drill bit for a particular feed rate.

4. Chip morphology depicted the type of chips produced during dry drilling of precipitation hardened stainless steel on the basis of that it can be concluded that adequate machining parameter for the drilling operation which is as such that feed should be 0.10 $\mathrm{mm} / \mathrm{rev}$ or lower than that should be applied at spindle speed of 2000 RPM. Also coated drill bit should be preferred.

\section{Conflict of interest}

\section{The author declares no conflict of interest.}

\section{References}

[1]. Bressan, J. D., Daros, D. P., Sokolowski, A., Mesquita, R. A., \& Barbosa, C. A. (2008). Influence of hardness on the wear resistance of 17-4 PH stainless steel evaluated by the pin-ondisc testing. Journal of Materials Processing Technology, 205 (1-3), 353-359.

[2]. Chen, W. C., \& Liu, X. D. (2000). Study on the various coated twist drills for stainless steels drilling. Journal of Materials Processing Technology, 99 (1-3), 226-230.

[3]. Chinchanikar, S., \& Choudhury, S. K. (2013). Investigations on machinability aspects of hardened AISI 4340 steel at different levels of hardness using coated carbide tools. International Journal of Refractory Metals and Hard Materials, 38 (1), 124-133.

[4]. Cicek, A., Uygur, I., Kıvak, T., \& Ozbek, N. A. (2012). Machinability of AISI 316 Austenitic Stainless Steel With Cryogenically Treated M35 High-Speed Steel Twist Drills. Journal of Manufacturing Science and Engineering, 134 (6), 1-6.
[5]. Dornfeld, D. A., Kim, J. S., Dechow, H., Hewson, J., \& Chen, L. J. (1999). Drilling Burr Formation in Titanium Alloy, Ti-6Al-4V. CIRP Annals-Manufacturing Technology, 48 (1), 73-76. [6]. Hsiao, C. N., Chiou, C. S., \& Yang, J. R. (2002). Aging reactions in a 17-4 PH stainless steel. Materials Chemistry and Physics, 74 (1), 134-142.

[7]. Lin, T. R. (2002). Cutting Behaviour Using Variable Feed and Variable Speed when Drilling Stainless Steel with TiN-Coated Carbide Drills. The International Journal of Advanced Manufacturing Technology, 19 (9), 629-636.

[8]. Lin, T. R. (2002). Experimental design and performance analysis of TiN-coated carbide tool in face milling stainless steel. Journal of Materials Processing Technology, 127 (1), 1-7.

[9]. Lin, X., Cao, Y., Wu, X., Yang, H., Chen, J., \& Huang, W. (2012). Microstructure and mechanical properties of laser forming repaired 17-4PH stainless steel. Materials Science and Engineering A , 553 (1), 80-88.

[10]. Minevich, A. A., Eizner, B. A., Gick, L. A., \& Popok, N. N. (2008). Case Studies on Tribological Behavior of Coated Cutting Tools. Tribology Transactions, 43 (4), 740-748.

[11]. Mohanty, A., Gangopadhyay, S., \& Thakur, A. (2016). On Applicability of Multilayer Coated Tool in Dry Machining of Aerospace Grade Stainless Steel. Materials and Manufacturing Processes, 31 (7), 869-879.

[12]. Murayama, M., Hono, K., \& Katayama, Y. (1999). Microstructural Evolution in a 17-4 PH Stainless Steel after Aging at 400C. Metallurgical and Materials Transactions A, 30 (2), 345-353.

[13]. OZCELIK, B., KURAM, E., DEMIRBAS, E., \& ,SIK, E. (2013). Effects of vegetable-based cutting fluids on the wear in drilling. Sadhana, 38 (4), 687-706. 
[14]. Sahoo, S., Thakur, A., \& Gangopadhyay, S. (2016). Application of Analytical Simulation on Various Characteristics of Hole Quality during Micro- Drilling of Printed Circuit Board. Materials and Manufacturing Processes, 31 (14), 1927-1934.

[15]. Sultan, A. Z., Sharif, S., \& Kurniawan, D. (2015). Chip Formation When Drilling AISI 316L Stainless Steel using Carbide Twist Drill. Procedia Manufacturing, 2 (1), 224-229.

[16]. Thakur, A., Gangopadhyay, S., \& Maity, K. P. (2014). Effect of cutting speed and CVD multilayer coating on machinability of Inconel 825. Surface Engineering, 30 (7), 516-523.

[17]. Thakur, A., Gangopadhyay, S., \& Mohanty, A. (2015). Investigation on Some Machinability Aspects of Inconel 825 during Dry Turning. Materials and Manufacturing Processes, 30 (8), 1026-1034.
[18]. Thakur, A., Gangopadhyay, S., Mohanty, A., \& Maity, K. (2016). Experimental assessment on performance of $\mathrm{TiN} / \mathrm{TiCN} / \mathrm{Al} 2 \mathrm{O} 3 / \mathrm{ZrCN}$ coated tool during dry machining of Nimonic C263. International Journal of Machining and Machinability of Materials, 18 (5-6), 452-465.

[19]. Uzhanfeng, L., \& Uquantai, L. (2018). Experimental study on deep hole drilling of 17 4PH material. Materials Science and Engineering, 307 (1), 1-6.

[20]. Viswanathan, U. K., Banerjee, S., \& Krishnan, R. (1988). Effects of Aging on the Microstructure of 17-4 PH Stainless Steel. Materials Science and Engineering , 104 (1), 181 189.

[21]. Yao, J., Wang, L., Zhang, Q., Kong, F., Lou, C., \& Chen, Z. (2008). Surface laser alloying of $17-4 \mathrm{PH}$ stainless steel steam turbine blades. Optics \& Laser Technology, 40 (6), 838-843. 